\title{
Comparative study on anointment promoted for Vitiligo Vis-À- Vis Tolenormointment in causing Immediate Pigment Darkening
}

\author{
Aruna.V, Priya. R,Satarupa Mukherjee,GayathriRajagopal \\ Dr. JRK's Siddha Research and Pharmaceuticals Pvt. Ltd, 18 \&19 Perumalkoil street, Kunrathur, Chennai- \\ 600069.
}

\begin{abstract}
The effect of an Ayurvedic formulation promoted for treatment of vitiligovis- a-visTolenorm ointment in triggering the genetic memory of the skin on exposure to sun was studied using Mexameter. Findings suggest that Tolenorm ointment elicit faster release of melanosomes to keratinocytes and simultaneously protecting the skin from sun damage. Irrespective of the extent of sun exposure,Tolenorm ointment triggers pigmentogenesis within 5 minutes indicating its rapid absorption. Details of the study are presented in the article.
\end{abstract}

Keywords: Immediate pigment darkening (IPD), Melanin, Sun exposure, Tolenorm, Vitiligo

\section{INTRODUCTION}

Immediate pigment darkening (IPD) is a transitory darkening phenomenon of the skin that occurs as a result of UVA/sun exposure. The melanocytic system is involved in the above development. It causes structural changes in melanocytes and keratinocytesthat cause chemical modification to the pre-existing melanin in the skin. The process of darkening startswith onset of sun exposure and it reaches the maximum threshold with time and then decreases rapidly when the stimulus is being ceased. [1, $2 \& 3]$ Astudy was planned to understand the effect of Ayurvedicointment which is promoted for vitiligovis-a- visTolenorm ointment (a proprietary Siddha formulation of Dr. JRK's Siddha Research and Pharmaceuticals Pvt. Ltd.,) on melanocytes to release its preformed melanin from melanosomes on sun exposure. The present study is also aimed to understand whether the test ointments could trigger the genetic memory of the skin when the skin is exposed to sun.Findings are presented in the paper.

\section{MATERIALS AND METHODS}

An Ayurvedic formulation in the market formulated with the herbs such as Calotropisgigantea, Psoraleacorylifolia, Ammimajus, Aloevera etc., promoted for treatment of vitiligo was procured and used for the study. Similarly, the proprietary Siddha medicine-Tolenorm ointment of Dr.JRK's Siddha Research of Pharmaceuticals Pvt., Ltd., Chennaiwas used for comparison. Tolenorm ointment contains the following siddha herbs such as Psoraleacorylifolia, WrightiatinctoriaandIndigoferatinctoria. [4]

\section{EVALUATION PROCEDURE}

A fingertip unit of both the market formulation and Tolenorm ointment were taken separately and applied over the pre- selected volar skin $\left(2 \mathrm{~cm}^{2}\right)$ of 11 volunteers. The ointment applied skin regions were then exposed to sun for 5, 10 and 15 minutes. Immediately after sun exposure, both melanin value and erythema value were recorded using mexameter and were compared with the respective values obtained from the skin regions exposed to sun without ointment. To counter check the effect of the above ointments, a fingertip unit of both the market formulation and Tolenorm ointment were applied over the skin and retained for 5, 10 and 15 minutes respectively without sun exposure. The readings of both melanin and erythema were recorded. [5]

\section{RESULTS}

Although 5 minutes of sun exposure was sufficient to trigger IPD but the maximum threshold was observed to be 15 minutes. After 15 minutes, the Ayurvedicointment has caused an increased pigmentation of 6.1. Interestingly the erythema value was also found to be high in the skin region where the above ointment was applied. Table- 1

In the case of Tolenorm ointment, the extent of increase of pigment was only 5.4. Interestingly the erythema value did not alter significantly. Further the melanin value also did not differ greatly between 10 and 15 minutes. Table- 2 
Table -1 Effect of Ayurvedic ointment in causing immediate pigment darkening in human volunteers

\begin{tabular}{|c|c|c|c|c|c|c|c|c|c|c|c|c|c|c|c|}
\hline \multirow{3}{*}{ S.no } & \multicolumn{2}{|c|}{$\begin{array}{c}\text { Control } \\
\text { (untreated) after } \\
15 \mathrm{~min}\end{array}$} & \multirow{3}{*}{$\%$ diff } & \multicolumn{2}{|c|}{$5 \mathrm{~min}$} & \multirow[t]{3}{*}{$\%$ diff } & \multicolumn{2}{|c|}{$10 \mathrm{~min}$} & \multirow[t]{3}{*}{$\%$ diff } & \multicolumn{6}{|c|}{$15 \mathrm{~min}$} \\
\hline & \multirow{2}{*}{$\mathrm{BF}$} & \multirow{2}{*}{$\mathrm{AF}$} & & \multirow{2}{*}{ BF } & \multirow{2}{*}{$\mathrm{AF}$} & & \multirow{2}{*}{$\mathrm{BF}$} & \multirow{2}{*}{$\mathrm{AF}$} & & \multicolumn{2}{|c|}{$\mathrm{BF}$} & \multicolumn{2}{|c|}{$\mathrm{AF}$} & \multicolumn{2}{|c|}{$\% \operatorname{diff}$} \\
\hline & & & & & & & & & & $\mathrm{M}$ & $E$ & $\mathrm{M}$ & $\mathrm{E}$ & $\mathrm{M}$ & $E$ \\
\hline 1 & 274 & 293 & -6.9 & 276 & 297 & -7.6 & 249 & 280 & -12.4 & 258 & 445 & 274 & 470 & -6.2 & -5.6 \\
\hline 2 & 454 & 462 & -1.8 & 374 & 395 & -5.6 & 347 & 379 & -9.2 & 360 & 355 & 395 & 390 & -9.7 & -9.9 \\
\hline 3 & 454 & 473 & -4.2 & 484 & 495 & -2.3 & 464 & 477 & -2.8 & 371 & 400 & 383 & 420 & -3.2 & -5.0 \\
\hline 4 & 501 & 504 & -0.6 & 484 & 509 & -5.2 & 503 & 541 & -7.6 & 426 & 480 & 435 & 495 & -2.1 & -3.1 \\
\hline 5 & 508 & 518 & -2.0 & 460 & 490 & -6.5 & 473 & 487 & -3.0 & 440 & 390 & 460 & 420 & -4.5 & -7.7 \\
\hline 6 & 513 & 525 & -2.3 & 431 & 444 & -3.0 & 400 & 425 & -6.3 & 386 & 476 & 408 & 495 & -5.7 & -4.0 \\
\hline 7 & 449 & 470 & -4.7 & 414 & 440 & -6.3 & 415 & 429 & -3.4 & 433 & 458 & 444 & 470 & -2.5 & -2.6 \\
\hline 8 & 480 & 494 & -2.9 & 485 & 483 & 0.4 & 494 & 505 & -2.2 & 547 & 375 & 600 & 395 & -9.7 & -5.3 \\
\hline 9 & 353 & 367 & -4.0 & 304 & 309 & -1.6 & 307 & 325 & -5.9 & 299 & 406 & 339 & 420 & -13 & -3.4 \\
\hline 10 & 502 & 520 & -3.6 & 445 & 508 & -14.2 & 480 & 510 & -6.3 & 470 & 421 & 481 & 430 & -2.3 & -2.1 \\
\hline 11 & 686 & 699 & -1.9 & 662 & 690 & -4.2 & 688 & 690 & -0.3 & 662 & 450 & 713 & 475 & -7.7 & -5.6 \\
\hline Avg & 470.4 & 484.1 & -3.2 & 438.1 & 460.0 & -5.1 & 438.2 & 458.9 & -5.4 & 422.9 & 423.3 & 448.4 & 443.6 & -6.1 & -4.9 \\
\hline
\end{tabular}

BF- BEFORE; AF- AFTER; M- MELANIN, E- ERYTHEMA

Table- 2 Effect of Tolenorm ointment in causing immediate pigment darkening in human volunteers

\begin{tabular}{|c|c|c|c|c|c|c|c|c|c|c|c|c|c|c|c|}
\hline \multirow{3}{*}{ S.No } & \multicolumn{2}{|c|}{$\begin{array}{l}\text { Control (untreated) } \\
\text { after } 15 \mathrm{~min}\end{array}$} & \multirow{3}{*}{$\begin{array}{l}\% \\
\text { diff }\end{array}$} & \multicolumn{2}{|c|}{$5 \mathrm{~min}$} & \multirow{3}{*}{$\begin{array}{c}\% \\
\text { diff }\end{array}$} & \multicolumn{2}{|c|}{$10 \mathrm{~min}$} & \multirow{3}{*}{$\begin{array}{c}\% \\
\text { diff }\end{array}$} & \multicolumn{6}{|c|}{$15 \mathrm{~min}$} \\
\hline & \multirow{2}{*}{ BF } & \multirow{2}{*}{$\mathrm{AF}$} & & \multirow{2}{*}{ BF } & \multirow{2}{*}{$\mathrm{AF}$} & & \multirow{2}{*}{$\mathrm{BF}$} & \multirow{2}{*}{$\mathrm{AF}$} & & \multicolumn{2}{|c|}{ Before } & \multicolumn{2}{|c|}{ After } & \multicolumn{2}{|c|}{$\%$ diff } \\
\hline & & & & & & & & & & $\mathrm{M}$ & $E$ & $\mathrm{M}$ & $E$ & $\mathrm{M}$ & $E$ \\
\hline 1 & 273 & 299 & -9.5 & 292 & 300 & -2.7 & 273 & 297 & -8.8 & 268 & 440 & 280 & 445 & -4.5 & -1.1 \\
\hline 2 & 440 & 465 & -5.7 & 330 & 345 & -4.5 & 357 & 376 & -5.3 & 329 & 399 & 350 & 400 & -6.4 & -0.3 \\
\hline 3 & 506 & 520 & -2.8 & 440 & 479 & -8.9 & 431 & 446 & -3.5 & 435 & 385 & 450 & 388 & -3.4 & -0.8 \\
\hline 4 & 452 & 480 & -6.2 & 527 & 558 & -5.9 & 515 & 538 & -4.5 & 458 & 480 & 470 & 490 & -2.6 & -2.1 \\
\hline 5 & 488 & 520 & -6.6 & 481 & 495 & -2.9 & 417 & 447 & -7.2 & 422 & 415 & 463 & 418 & -9.7 & -0.7 \\
\hline 6 & 513 & 525 & -2.3 & 450 & 480 & -6.7 & 400 & 439 & -9.8 & 406 & 456 & 428 & 460 & -5.4 & -0.9 \\
\hline 7 & 443 & 453 & -2.3 & 416 & 440 & -5.8 & 402 & 415 & -3.2 & 462 & 449 & 475 & 450 & -2.8 & -0.2 \\
\hline 8 & 465 & 472 & -1.5 & 466 & 480 & -3.0 & 489 & 517 & -5.7 & 426 & 389 & 440 & 390 & -3.3 & -0.3 \\
\hline 9 & 306 & 324 & -5.9 & 329 & 346 & -5.2 & 326 & 337 & -3.4 & 331 & 411 & 356 & 415 & -7.6 & -1.0 \\
\hline 10 & 518 & 525 & -1.4 & 500 & 518 & -3.6 & 476 & 496 & -4.2 & 429 & 447 & 458 & 452 & -6.8 & -1.1 \\
\hline 11 & 671 & 688 & -2.5 & 644 & 670 & -4.0 & 690 & 705 & -2.2 & 655 & 399 & 700 & 400 & -6.9 & -0.3 \\
\hline Avg & 461.4 & 479.2 & -4.2 & 443.2 & 464.6 & -4.8 & 434.2 & 455.7 & -5.2 & 420.1 & 424.5 & 442.7 & 428.0 & -5.4 & -0.8 \\
\hline
\end{tabular}

\section{DISCUSSION}

The increased pigmentation and increased erythema value as induced by the Ayurvedic ointment suggests the likely higher risk factor associated with the formulation. The Ayurvedic ointment under study may not be offering sun protection but may be causing high skin sensitivity. Whereas the Tolenorm ointment seems to trigger not only IPD but also offers sun protection therefore the erythema value did not alter significantly.

The question of how Tolenorm ointment accelerates IPD when it protects the skin from sun is quite intriguing. We presume that the sun protection factor of Tolenorm ointment may be slow acting and therefore on longer exposure to sun the desired sun protection is happening. The other possible reason as we presume is that some constituents in Tolenorm may be eliciting melanosome transfer without any trigger from sunlight. Nevertheless both the possibilities clearly indicate the faster absorption of Tolenorm ointment. To confirm the above hypothesis we did check the melanin value in the skin after usage of both Ayurvedic ointment and Tolenorm ointment without sun exposure (after 5, 10 and 15 minutes). Interestingly we have obtained an increased melanin value of 1.3 for Tolenorm ointment (without sun exposure) whereas no such increase was observed for Ayurvedic ointment. Further the increased in melanin value was observed within 5 minutes and which remain constant for 15 minutes. Findings of the present study clearly suggest that for vitiligenious skin, the Tolenorm ointment may be more effective and safe as well when compared to the formulation that may not have sun protection effect. Tolenorm may elicit the auto pigmentogenesis mechanism of the skin that is responsible for IPD without the influence of sun exposure. Tolenorm also offers sun protection to the skin which is extremely necessary for vitiligo patients. 


\section{REFERENCES}

[1] Herbert Hönigsmann, Gerold Schuler Werner Aberer et al.(1986).Immediate Pigment Darkening Phenomenon. A Re-evaluation of Its Mechanisms.Journal of Investigative Dermatology. Volume 87(5); 648-652

[2] Routaboul C, Denis A, Vinche A.(1999). Immediate pigment darkening: description, kinetic and biological function.Eur J Dermatol. 9(2):95-9.

[3] Kays H. Kaidbey, Angelit Barnes. (1991).Determination of UVA protection factors by means of immediate pigment darkening in normal skin. Journal of the American Academy of Dermatology. Volume 25(2): Part 1: 262-266

[4] Ravichandran F, Jayaraman N. Efficacy of topical application of Tolenorm oil or ointment in the management foVitiligo. Dermavision beyond 2000, Banglore, Karnataka.

[5] M. Arunothayam, Krishnamoorthy.J.R, GayathriRajagopal, Ranganathan.S.(2012).Dermal melanogenesis in response to combination of Curcuma zedoaria and Aloe vera - A Mexameter base evaluation. Journal of Applied cometology.30, 129-136. 